\title{
Grant program for the division of computer research: National Science Foundation
}

WALTER A. SEDELOW, JR.

Division of Mathematical and Computer Sciences, National Science Foundation, Washington, D.C. 20550

Requests for further information as to Computer Science programs at the National Science Foundation should be directed to: Computer Science Section, Division of Mathematical and Computer Sciences, National Science Foundation, Washington, D.C. 20550. 